\title{
Rapid sequence induction: where did the consensus go?
}

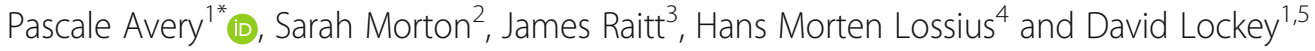

\begin{abstract}
Background: Rapid Sequence Induction (RSI) was introduced to minimise the risk of aspiration of gastric contents during emergency tracheal intubation. It consisted of induction with the use of thiopentone and suxamethonium with the application of cricoid pressure.

This narrative review describes how traditional RSI has been modified in the UK and elsewhere, aiming to deliver safe and effective emergency anaesthesia outside the operating room environment. Most of the key aspects of traditional RSI - training, technique, drugs and equipment have been challenged and often significantly changed since the procedure was first described. Alterations have been made to improve the safety and quality of the intervention while retaining the principles of rapidly securing a definitive airway and avoiding gastric aspiration. RSI is no longer achieved by an anaesthetist alone and can be delivered safely in a variety of settings, including in the pre-hospital environment.

Conclusion: The conduct of RSI in current emergency practice is far removed from the original descriptions of the procedure. Despite this, the principles - rapid delivery of a definitive airway and avoiding aspiration, are still highly relevant and the indications for RSI remain relatively unchanged.
\end{abstract}

Keywords: Rapid sequence induction, Emergency anaesthesia, Standard operating procedures, Apnoeic oxygenation, Video laryngoscopy, Governance

\section{The background to RSI}

Rapid induction of anaesthesia and tracheal intubation is used in the management of critically unwell patients to address the long-recognised risk of aspiration of gastric contents and unnecessary morbidity and mortality $[1,2]$. Rapid Sequence Induction (RSI) of anaesthesia was described in 1970 by Stept and Safar. It followed the work by Sellick on the use of cricoid pressure to prevent reflux of gastric contents during induction $[1,3]$. The traditional method describes: denitrogenation of the lungs with $100 \%$ oxygen for at least 2 min, induction with a pre-determined dose of thiopentone, application of cricoid pressure, administration of a pre-determined dose of suxamethonium, a period of apnoea with no

\footnotetext{
* Correspondence: pascale.avery@nhs.net

${ }^{1}$ Southmead Hospital, North Bristol NHS Trust, Bristol BS10 5NB, UK

Full list of author information is available at the end of the article
}

positive pressure ventilation, tracheal intubation with a cuffed tracheal tube, and the release of cricoid pressure when tube placement is successfully confirmed. This led to a remarkably consistent approach to emergency anaesthesia for many years and this technique is still widely practiced in many countries. However, in recent years this consensus has rapidly declined and the emergency anaesthesia literature has revealed considerable variation and controversy in how the intervention is delivered [47]. Almost every element of the original technique has been challenged or adapted. This may be because little good evidence has been published since the original description to indicate that traditional RSI effectively reduces aspiration or improves patient outcomes [8]. Alternatively, it may be that emergency anaesthesia has simply evolved with developments in anaesthesia and emergency medicine in terms of technique, training and

(c) The Author(s). 2021 Open Access This article is licensed under a Creative Commons Attribution 4.0 International License, which permits use, sharing, adaptation, distribution and reproduction in any medium or format, as long as you give appropriate credit to the original author(s) and the source, provide a link to the Creative Commons licence, and indicate if changes were made. The images or other third party material in this article are included in the article's Creative Commons licence, unless indicated otherwise in a credit line to the material. If material is not included in the article's Creative Commons licence and your intended use is not permitted by statutory regulation or exceeds the permitted use, you will need to obtain permission directly from the copyright holder. To view a copy of this licence, visit http://creativecommons.org/licenses/by/4.0/. The Creative Commons Public Domain Dedication waiver (http://creativecommons.org/publicdomain/zero/1.0/) applies to the data made available in this article, unless otherwise stated in a credit line to the data. 
new drugs and equipment. An ambitious recent systematic review of the limited available high quality evidence attempted to establish which factors improved or failed to improve the success and safety of RSI [9]. It identified key factors as oxygenation strategies, patient position, choice of drugs, checklists and use of videolaryngoscopy. In this narrative review, we will aim to describe how the traditional RSI has evolved and how these and other factors have led to the extensive modification of the standard RSI technique in the UK and elsewhere. We have not specifically addressed RSI in children but many of the same issues apply.

\section{Methodology}

PubMed, Web of Science, Cochrane, OVID, and Embase were searched electronically for relevant articles using Medical Subject Heading (MeSH) terms relevant to each sub-section of the article. For example, "Rapid Sequence Induction OR RSI" AND "checklists OR SOPS OR standard operating procedures OR guidelines". Titles and abstracts were screened for papers of relevance by two authors (PA and SM). Reference lists of included articles were screened for relevant titles. Articles were then reviewed by two authors (PA and SM) to ensure sufficient quality before being included in the review; if there was any disagreement a third author (DL) was included in the decision.

\section{The indications for RSI}

Although the technique of RSI has evolved, the indications for RSI have remained essentially unchanged for many years. The aim of RSI is to deliver anaesthesia with muscle relaxation to achieve rapid intubation with the prevention of aspiration of gastric contents [10], and most of the many indications for an RSI outside the operating theatre have been categorised using an $\mathrm{ABCDE}$ approach (Table 1), with the "A" and " $\mathrm{B}$ " indications often recognised as the more common indications [11].

\section{RSI outside the operating theatre}

RSI was originally described in an operating theatre environment, but it is no longer only delivered there.

Table 1 Indications for RSI

\footnotetext{
- Airway - loss of airway patency

- Breathing - inadequate ventilation, respiratory failure or hypoxia

- Circulation - improve oxygen delivery in hypovolaemia or allow haemorrhage control procedures

- Disability - neuroprotection particularly in traumatic brain injury, reduced Glasgow Coma Score, status epilepticus, post cardiac arrest protection

- Everything else - e.g. emergency surgery, humanitarian indications, temperature control (e.g. serotonin syndrome), to facilitate safe transfer.
}

Within hospitals, there remains variation between speciality operating theatres, with obstetric theatres still reporting the highest use of a "traditional RSI" [6] among the relatively small numbers of patients receiving general anaesthesia for delivery. The concept of 'critical care without walls' - where key critical care interventions are delivered wherever required - has resulted in RSI frequently being performed outside the operating theatre in the emergency department (ED), intensive care unit (ICU) and in pre-hospital settings [12, 13]. The frequently acknowledged challenges with anaesthesia outside the operating theatre include unfamiliar environments, teams, and equipment [14]. The NAP4 study (Major complications of airway management in the United Kingdom) reported that complications outside the operating theatre are common and that one in four major airway adverse events in a hospital are likely to occur in ICU or the ED [15]. Although the case mix of emergency patients anaesthetised outside the operating theatre is always likely to result in higher risk and an increased risk of complications, the number of adverse events may be reduced by improving the standard of airway management. Recent UK guidelines on pre-hospital anaesthesia emphasise that even when anaesthesia is delivered in the pre-hospital phase of care the standards of practice should be similar to those in the emergency department [14].

\section{Who delivers RSI?}

Traditional RSI was delivered by anaesthetists. Emergency anaesthesia is no longer the exclusive reserve of the anaesthetist although in European countries they still deliver the vast majority of procedures. A minority of emergency physicians in the UK have undertaken training in anaesthesia and are able to deliver emergency anaesthesia in the emergency department or as part of a pre-hospital doctor-paramedic team. Emergency anaesthesia conducted by emergency physicians is much more common in some other systems. The Australian and New Zealand Emergency Department Airway Registry (ANZEDAR) reported 3710 intubations carried out over 2 years in 43 emergency departments. $72 \%$ were carried out by emergency physicians and the $84.3 \%$ first pass intubation success rate is comparable to that reported in studies where intubation was carried out by anaesthetists. The authors do however comment on the significant (26\%) adverse event rate. A similar first pass intubation success was reported in Scotland in 3738 patients, $72 \%$ of whom were intubated by emergency physicians. In this series a system had developed where emergency physicians and anaesthetists were both present and collaborated in advanced airway management [16]. 
The UK Royal College of Anaesthetists stipulates that physicians should perform an Initial Assessment of Competence after a 3 month period prior to being able to give anaesthetics without direct supervision [17]. PreHospital Emergency Anaesthesia (PHEA) is usually delivered by a trained team of physician and paramedic and requires additional training, with physicians expected to have completed a minimum of 6 months anaesthetic experience [18, 19]. Drug-assisted paramedic intubation rarely takes place in the UK, although some critical care paramedics may perform advanced airway techniques in a pre-hospital cardiac arrest situation if supraglottic airway devices fail [20]. One US study suggests that at least 25 previous intubation attempts result in an improved first pass intubation rate, with at least 4 weeks of intense training required to achieve this [21].

The evidence reporting intubation success rates and complications by provider type is often of low quality and with considerable heterogeneity between systems. Two meta-analyses of the available evidence demonstrated significantly higher failed intubation rates and adverse events for non-physicians when compared with physicians [22, 23]. This is likely to reflect experience and often low numbers of intubations per provider in emergency pre-hospital practice. Most pre-hospital providers are unlikely to achieve and maintain high success rates without in-hospital training and ongoing practice. Most existing evidence confirms better results with increased experience and numbers of regular intubations $[24,25]$. RSI will likely continue to be delivered by an increased variety of providers and the quality of care and intubation success will be dependent on competency influenced by experience, training and relevant continuing professional development. One consistent feature of RSI delivery in high performance systems is that it is delivered by a team rather than an individual provider.

\section{Checklists and standard operating procedures in RSI}

Until relatively recently standard operating procedures and checklists were rarely used in the conduct of RSI in emergency practice. Both are now routinely used in prehospital practice and emergency departments in many areas. In a 2017 survey of UK pre-hospital critical care teams that provided RSI, $80 \%$ had an RSI SOP and $83 \%$ used a checklist [26]. These tools promote a shared mental model of the procedure by the attending team, promote planning for any problems encountered and prevent equipment and preparation errors.

Standard operating procedures (SOP) and checklists have been shown to reduce error and improve patient safety within healthcare systems. One of the best examples of a successful checklist is the World Health Organization (WHO) Surgical Safety Checklist developed by the WHO as part of its Global Patient Safety Challenge.
Implementation of the checklist was associated with rapid reductions in mortality and complications among patients who were undergoing surgery $[27,28]$. Reductions in complication rates have been reported after the introduction of RSI checklists applied to emergency intubation in the emergency department [29], and in the intensive care unit [30]. However, it is important to understand the limitations of checklist use. They may effectively reduce some complications, for example, equipment and preparation errors but are not a substitute for technical skill and experience. They also do not necessarily modify the presence of difficult patient factors. This may account for some recent studies which report a lack of effect in some clinical endpoints after the implementation of checklists in emergency intubation practice [30-32]. A recent study in prehospital practice among experienced Scandinavian providers reported benefits and disadvantages in checklist use as well as highlighting considerable variation in checklist practice [33]. Checklists are likely to remain a key component of emergency intubation, but they are less likely to be effective when used in isolation rather than as a part of a well-rehearsed process conducted by an experienced team [34]. In addition, all checklists are not equal - they need to be carefully designed to be effective. This includes careful consideration of length, content and design to maximise benefit and uptake by providers $[35,36]$.

Airway guidelines are now widely available and benchmark practice in most countries. Examples are the Difficult Airway Society (DAS) guidelines for in-hospital intubation which include critically ill, obstetric, paediatric and intensive care patients $[37,38]$. In the pre-hospital environment guidelines promote simple reproducible techniques combined with checklists and a "challengeresponse" approach to ensure steps are not missed [18]. The development of guidelines and checklists delivered as part of a 'quality bundle' to cover most aspects of emergency airway management in most clinical areas has been a key factor in the evolution of the conduct of RSI.

\section{Drugs}

The traditional induction agents for Rapid Sequence Induction (RSI) of anaesthesia were thiopentone and suxamethonium, with doses calculated prior to commencing induction [8]. This technique is still used in emergency obstetric anaesthesia [5] although the use of thiopentone without opiates during RSI has been associated with a high risk of accidental awareness [39].

In other emergency practice the use of thiopentone and suxamethonium has become much less common and in some systems disappeared altogether.

Although departure from this standard practice has been rapid it has not been replaced by consistent practice. One relatively common feature of current practice is the addition of an opiate agent to the induction agent 
and muscle relaxant. Opiates are frequently used as coinduction agents in both hospital and pre-hospital settings, allowing the use of lower doses of hypnotics to promote haemodynamic stability and minimise increases in peri-intubation intracranial pressure. A recent national survey of anaesthetists reported that $80 \%$ used an opioid at induction [5, 38].

In the operating theatre setting propofol is now a preferred agent for induction in RSI. Outside the operating theatre the drug combination of fentanyl, ketamine and rocuronium for emergency anaesthesia, particularly in a pre-hospital setting, has become widespread UK practice [40]. The historical concerns regarding ketamine and raised intracranial pressure have now been widely rejected $[41,42]$ and there are guidelines which favour the use of ketamine in critically ill patients due to its haemodynamic stability [38]. While ketamine use has increased, the use of etomidate has sharply decreased in many countries in the same period. Etomidate was considered an induction agent with minimal haemodynamic effects but has fallen out of favour in hospital and critical care because of its adrenocortical suppression side effects. There is little evidence for harmful adrenocortical suppression after a single induction dose of etomidate but it seems unlikely that use of this agent will increase back to previous levels [43].

The importance of "adequate neuromuscular blockade" is a key point stressed in the DAS airway guidelines to avoid difficult intubating conditions [37, 44]. The reduction of the use of the short acting depolarizing muscle relaxant suxamethonium which was associated with excellent intubating conditions has been dramatic. This was driven by the introduction of rocuronium into anaesthetic practice which, when administered at high doses, has a much more rapid onset of action than older non-depolarizing agents. Studies comparing the two agents have failed to show significant differences in intubation success or complications [44], although a Cochrane review in 2015 still narrowly favoured the use of suxamethonium for RSI [45]. In the same year a survey of UK pre-hospital practice reported $41 \%$ of services using rocuronium for RSI and this has likely increased significantly in subsequent years [46]. The development of sugammadex, an agent which can rapidly reverse the effects of rocuronium [47] has been suggested as a reason why RSI is now frequently conducted with rocuronium. In fact, rocuronium was being used for RSI before the introduction of sugammadex and a large proportion of critically ill patients are not in the patient population where 'waking' after failed intubation is an option [4]. Sugammadex is rarely carried by pre-hospital services [46]. The confidence to use a long acting muscle relaxant may be increased by the very high success rates of airway rescue techniques reported after failed intubation in recent large studies, even in the resource-poor prehospital environment [46, 48].

Drug use for RSI has not only changed significantly since the original descriptions of RSI but internationally reported practice demonstrates major variations. A prospective study of 3710 medical and trauma intubations in 43 emergency departments in Australia and New Zealand in 2017 mostly by emergency physicians reported that propofol, thiopentone or ketamine were used with similar frequency for induction, and suxamethonium was still the most commonly used muscle relaxant [49]. In German pre-hospital practice when a total of 9720 RSIs were examined over a 10 year period dramatic reductions in etomidate were reported with a rise in propofol and ketamine use [50]. Fentanyl was the most commonly administered opiate but sufentanil was also increasingly used. These studies demonstrate that even within countries the use of drugs for RSI are very varied and there is little consensus on which combination of agents is ideal. An alternative view might be that expert practitioners are increasingly tailoring their anaesthetic techniques to specific patient groups.

\section{Pre-induction sedation}

Patients requiring emergency anaesthesia are sometimes agitated or noncompliant due to trauma or critical illness. In order to achieve safe and effective conditions for monitoring, pre-oxygenation and induction of anaesthesia it may be necessary to sedate the patient with a small dose of the intended induction drug or another sedative agent. This is essentially procedural sedation to achieve suitable conditions for induction of anaesthesia. This technique is in conflict with traditional RSI where no agents are administered before induction but was described in UK pre-hospital anaesthesia guidelines in 2009 and again in 2017 [18]. A safety feature of the technique is that sedation is only administered when preparation for RSI is completed.

\section{Cricoid pressure}

Cricoid pressure was introduced into clinical practice as a key element of RSI in 1961, based mainly on a small case series on cadavers [1]. It is used to compress the oesophagus and prevent regurgitation of gastric contents until the airway is secured with a tracheal tube. Many anaesthetists also use it to manipulate the upper airway to improve laryngeal view. A pressure of $20-40 \mathrm{~N}$ is cited as the amount of pressure that should be applied [10]. There is a growing scepticism about the efficacy of cricoid pressure during emergency anaesthesia. A Cochrane review published in 2015 noted the lack of high quality evidence on the subject but acknowledged that what evidence there was did not strongly support the intervention [51]. Subsequently a multicentre 
randomized, double-blind, study conducted in the US was published in 2019 and demonstrated that in 3472 patients who had emergency RSI the use of cricoid pressure did not reduce the incidence of aspiration. It also suggested that intubation was more difficult in the cricoid pressure group [52]. There is a school of thought that if cricoid pressure is used it may inhibit air entry into the stomach. Therefore ventilation during the apnoeic period following drug administration may be less likely to provoke aspiration. The UK is one of only a few countries with a high use of cricoid pressure particularly compared to other European countries [53]. UK DAS guidelines recommend the early removal of cricoid pressure if there is a difficult laryngoscopy [37]. Other national and international guidelines including those by the European Resuscitation Council, Scandinavian Clinical Practice Guidelines, and German Airway Management Guidelines do not support its use [54-56].

The use of cricoid pressure as an essential component of RSI is decreasing. When it is used it is widely recommended that it should be rapidly released in the event of a poor view at laryngoscopy.

\section{Peri-induction oxygenation}

There is recognition that the balance of risk between aspiration and hypoxia was not addressed by the traditional RSI method. This is particularly important for critically ill patients who are at high risk of becoming hypoxic during the apnoeic period of induction [57]. This has led to the development of simple techniques to maintain oxygenation.

Nasal apnoeic oxygenation can be delivered by high flow oxygen (10-15 L/min) through nasal cannulae and has been shown to significantly increase the time to desaturation during the apnoeic period of induction [58, 59]. The development of transnasal humidified rapidinsufflation ventilatory exchange (THRIVE) has also been used to maintain oxygenation although mostly in the operating theatre environment $[60,61]$. In nonoperating theatre environments, it has been clearly demonstrated that apnoeic oxygenation is straightforward to deliver. Where the airway is patent it would be fully expected to increase the time to desaturation and this has been confirmed in the pre-hospital environment [62]. Unfortunately, clear benefit has not been demonstrated in more recent studies [63, 64]. On the basis that apnoeic oxygenation is likely to delay the onset of hypoxaemia in some patient groups and is easy to deliver, it is likely to continue to be used in emergency practice. A different approach to the prevention of hypoxia in the apnoeic period is to avoid apnoea during induction altogether. A large multicentre trial showed that gentle bag valve mask ventilation between induction and laryngoscopy reduced the incidence of hypoxia without adversely affecting aspiration rates [65]. This practice may already have been commonplace. In 2016, 17\% of UK anaesthetists surveyed performed gentle mask ventilation during the apnoeic period during emergency RSI [5].

Another simple technique to improve oxygenation during emergency anaesthesia is to optimise patient positioning. In addition to improving oxygenation a head up position has been recommended to prevent aspiration and improve intubation success [38]. However, a recent study randomised patients undergoing emergency RSI to a ' $25^{\circ}$ ramped up' position and compared them to patients in the standard supine position. The authors were unable to demonstrate any benefits in oxygenation and also reported significantly worse laryngoscopic views and increased intubation difficulty [66]. The benefits or disadvantages of a head up position are not therefore clear. There are other positioning considerations which can also influence intubation difficulty including removal of cervical collars and ensuring, in the pre-hospital environment, 360-degree access to the patient and the use of an ambulance trolley at waist height to optimise laryngoscopy attempts [18]. The ability to tip a trolley is also desirable [10].

Simple strategies to maintain oxygenation and improve the laryngoscopic view have been incorporated into emergency RSI techniques. Although the benefits have not been straightforward to establish, the available evidence suggests that adaptations do not cause increased risk of complications such as aspiration.

\section{Equipment developments Laryngoscopy}

The increasing availability and portability of video laryngoscopes has led to a significant increase in their use in emergency anaesthesia including in emergency departments and pre-hospital care. A Cochrane review published in 2016 examined over 60 studies and concluded that video laryngoscopy can improve laryngoscopic view and reduce failed intubation rates particularly in patients with difficult airways. Only three studies included emergency patients [67]. The published evidence for the value of video laryngoscopy over direct laryngoscopy in emergency anaesthesia is inconclusive and the quality of available evidence is low [67]. Indeed, one study showed no difference between direct and video laryngoscopy in survival to hospital discharge in trauma patients and showed a longer median time to intubation; sub-group analysis of severe head injury patients seemed to be associated with a greater incidence of hypoxia during the intubation attempt [68]. There is however consensus that, in the airway management of critically ill patients videolaryngoscopy should be immediately available [38] The benefits of availability were confirmed in a recent 
randomised pre-hospital study which found both direct and indirect laryngoscopy to be equally effective but reported that swapping from one technique to the other was more successful than a second attempt with the same device [69].

Despite the fact that intubation difficulties are more likely to occur outside the operating theatre environment a recent survey reported that video laryngoscopes are most commonly available in operating rooms and less so in the areas where emergency anaesthesia is performed outside the operating room [70]. The potential risks of transmission of infection during emergency intubation have been brought into sharp focus during the COVID-19 pandemic. UK guidelines recommend videolaryngoscopy as the first line option for emergency intubation in high risk patients [71].

\section{Intubating bougie}

Since the description of RSI the use of an intubating bougie has become standard UK practice to optimise the first attempt of emergency tracheal intubation during both direct and video laryngoscopy [19, 72, 73]. The simple device is used variably in other countries, but some recent high-quality studies have demonstrated superiority over other intubation techniques [74].

\section{Monitoring}

Advances in the standard of monitoring equipment have transformed the conduct of emergency anaesthesia. There are well developed minimum monitoring national standards in place for elective and emergency anaesthesia and almost identical standards are recommended for pre-hospital anaesthesia [18]. The use of capnography to detect oesophageal intubation is a key improvement in the conduct of RSI and has been identified as a vital tool in the prevention of life threatening complications in emergency intubation $[15,75]$. In patients requiring neuroprotection, invasive blood pressure monitoring may be indicated to prevent both hypo and hypertension [76].

\section{Management of failed intubation after RSI}

The developments in equipment, monitoring and techniques have made failed intubation after RSI less common. When intubation does fail rescue techniques have developed to make poor outcomes less likely. The development of supraglottic airways have made a proportion of 'can't intubate, can't ventilate' situations much easier to manage and the use of familiar failed intubation guidelines have reduced hypoxic time and the speed at which rescue techniques, including rescue surgical airway, are performed [37]. Recent studies have also suggested a fall in the rates of rescue surgical airway both in emergency departments [77] and in pre-hospital practice [78].

\section{Governance of RSI}

In most well-resourced hospitals and emergency medical systems the conduct of RSI is subject to multiple governance processes which were not present when RSI was introduced. Training, supervision, guidelines, and incident reporting are just some of the governance elements which aim to deliver safer emergency anaesthesia. Registries and databases provide information to guide quality improvement and major multicentre national audit projects have identified key areas for improvement of the RSI process, particularly around airway complications and awareness $[15,39]$. More recently this activity has extended to more the difficult areas of emergency anaesthesia in the emergency department and in pre-hospital care [14] and individual services have adopted quality improvement recommendations such as key performance indicators for pre-hospital anaesthesia [75].

\section{Conclusions}

In many respects the conduct of RSI in current emergency practice is far removed from the original descriptions of the procedure. Despite this, the principles rapid delivery of a definitive airway and avoiding aspiration, are still highly relevant and the indications for RSI remain relatively unchanged. Changes to the procedure have tackled several considerations less well addressed by the original technique including reducing the frequency and severity of hypoxaemia, reducing the frequency of failed intubation and making detection and management of complications more effective. The remarkable consensus in RSI practice that persisted for many years has lessened in recent years. Despite this, standardisation is often in place in many systems. It is difficult to know whether variations in practice are necessary to deliver tailored care to different patient groups or whether increased consistency has the potential to improve overall patient safety. In in-hospital practice it has been suggested that avoidance of adverse events and successful intubation of critically ill patients on the first attempt can be positively influenced by operator related factors including training and experience, equipment selection and drug choices [79]. Limiting choice and delivering a very standard RSI might be more appropriate when RSI is delivered by less experienced operators in more austere environments [14]. One consistency in high performing systems is the recognition that the delivery of high-quality RSI is not a solo activity and requires an effective team approach to apply the appropriate techniques. In addition, attention to all factors in RSI delivery is important. Systems reporting improvement rarely introduce or change only one component of the procedure. Usually a 'bundle' of improvements has been required to address all aspects of the procedure and deliver improved quality $[34,80]$. 
The safety of RSI is as important now as it was when first described. It is carried out on our sickest and most unstable patients in all emergency treatment areas. Choices of drugs and techniques have rapidly increased and many of these changes have the potential to improve safety. Providers of RSI now have a wide range of tools and techniques available to enhance the basic procedure. These can be incorporated into a structured plan to deliver safe emergency anaesthesia to their particular patient casemix.

\section{Abbreviations}

RSI: Rapid Sequence Induction; DAS: Difficult Airway Society; GCS: Glasgow Coma Score; WHO: World Health Organisation; SOP: Standard Operating Procedures; PHEA: Pre-Hospital Emergency AnaesthesiaEDEmergency Department; ICU: Intensive Care Unit; NAP: National Audit Project

\section{Acknowledgements}

There are no acknowledgements.

\section{Authors' contributions}

PA, SM, JR drafted the initial manuscript. DL, HML provided feedback and editing. All authors agreed on the final draft.

\section{Funding}

No funding was received for this review.

\section{Availability of data and materials}

Data sharing not applicable to this article as no datasets were generated or analysed during the current study.

\section{Declarations}

\section{Ethics approval}

Not applicable.

\section{Consent for publication}

Not applicable.

\section{Competing interests}

The authors declare that they have no competing interests.

\begin{abstract}
Author details
${ }^{1}$ Southmead Hospital, North Bristol NHS Trust, Bristol BS10 5NB, UK. ${ }^{2}$ Essex \& Herts Air Ambulance, Flight House, Earls Colne, Colchester, Essex CO6 2NS, UK. ${ }^{3}$ Thames Valley Air Ambulance Stokenchurch House, Oxford Rd, Stokenchurch, High Wycombe HP14 3SX, UK. ${ }^{4}$ Norwegian Air Ambulance Foundation, Holterveien 24, 1441 Drøbak, Norway. ${ }^{5}$ Blizard Institute, Queen Mary University, Whitechapel, London E1 2AT, UK.
\end{abstract}

Received: 4 March 2021 Accepted: 28 April 2021

Published online: 13 May 2021

\section{References}

1. Sellick BA. Cricoid pressure to control regurgitation of stomach contents during induction of anaesthesia. Lancet. 1961;2(7199):404-6. https://doi. org/10.1016/s0140-6736(61)92485-0.

2. Mendelson $\mathrm{CL}$. The aspiration of stomach contents into the lungs during obstetric anesthesia. Am J Obstet Gynecol. 1946;52(2):191-205. https://doi. org/10.1016/50002-9378(16)39829-5.

3. Stept WJ, Safar P. Rapid induction-intubation for prevention of gastriccontent aspiration. Anesth Analg. 1970;49(4):633-6.

4. Morris J, Cook TM. Rapid sequence induction: a national survey of practice. Anaesthesia. 2001;56(11):1090-7. https://doi.org/10.1046/j.1365-2 044.2001.01962.x

5. Sajayan A, Wicker J, Ungureanu N, Mendonca C, Kimani PK. Current practice of rapid sequence induction of anaesthesia in the UK - a national survey. Br J Anaesth. 2016;117:69-74.
6. Koerber JP, Roberts GEW, Whitaker R, Thorpe CM. Variation in rapid sequence induction techniques: current practice in Wales. Anaesthesia. 2009;64(1):54-9. https://doi.org/10.1111/j.1365-2044.2008.05681.x.

7. El-Orbany M, Connolly LA. Rapid sequence induction and intubation: current controversy. Anesth Analg. 2010;110(5):1318-25. https://doi.org/1 0.1213/ANE.0b013e3181d5ae47.

8. Wallace $C$, McGuire B. Rapid sequence induction: its place in modern anaesthesia. Continuining Educ Anaesth Crit Care Pain. 2013;14(3):130-5.

9. Cabrini L, Landoni G, Baiardo Redaelli M, Saleh O, Votta CD, Fominskiy E, et al. Tracheal intubation in critically ill patients: a comprehensive systematic review of randomized trials. Crit Care. 2018;22(1):6. https://doi.org/10.1186/ s13054-017-1927-3.

10. Sinclair R, Luxton M. Rapid sequence induction. Continuining Educ Anaesth Crit Care Pain. 2005;5(2):45-8. https://doi.org/10.1093/bjaceaccp/mki016.

11. Reid C, Chan L, Tweeddale M. The who, where, and what of rapid sequence intubation: prospective observational study of emergency RSI outside the operating theatre. Emerg Med J. 2004;21(3):296-301. https://doi.org/10.113 6/emj.2003.007344.

12. Turner J, Bourn S, Raitt J, Ley E, O'Meara M, Pre-HOspital Trainee Operated research Network study investigators. Pre-hospital emergency anaesthesia in the United Kingdom: an observational cohort study. Br J Anaesth. 2020; 124(5):579-84. https://doi.org/10.1016/j.bja.2020.01.023.

13. Hillman K. Critical care without walls. Curr Opin Crit Care. 2002;8(6):594-9. https://doi.org/10.1097/00075198-200212000-00019.

14. Asai T. Airway management inside and outside operating roomscircumstances are quite different. Br J Anaesth. 2018;120(2):207-9. https:// doi.org/10.1016/j.bja.2017.10.010.

15. Cook TM, Woodall N, Harper J, Benger J, Fourth National Audit Project. Major complications of airway management in the UK: results of the fourth National Audit Project of the Royal College of Anaesthetists and the difficult airway society. Part 2: intensive care and emergency departments. $\mathrm{Br} J$ Anaesth. 2011;106(5):632-42. https://doi.org/10.1093/bja/aer059.

16. Kerslake D, Oglesby AJ, Di Rollo N, James E, McKeown DW, Ray DC, et al. Tracheal intubation in an urban emergency department in Scotland: a prospective, observational study of 3738 intubations. Resuscitation. 2015;89: 20-4. https://doi.org/10.1016/j.resuscitation.2015.01.005.

17. Royal College of Anaesthetists. Initial Assessment of Competencies (IAC). 2020. https://rcoa.ac.uk/training-careers/training-anaesthesia. Accessed 22 Jan 2021.

18. Lockey DJ, Crewdson K, Davies G, Jenkins B, Klein J, Laird C, et al. AAGBI: safer pre-hospital anaesthesia 2017: Association of Anaesthetists of Great Britain and Ireland. Anaesthesia. 2017;72(3):379-90. https://doi.org/10.1111/anae.13779.

19. Crewdson K, Lockey D, Voelckel W, Temesvari P, Lossius HM, EHAC Medical Working Group. Best practice advice on pre-hospital emergency anaesthesia \& advanced airway management. Scand J Trauma Resusc Emerg Med. 2019;27(1):6,

20. Deakin CD, Clarke T, Nolan J, Zideman DA, Gwinnutt C, Moore F, et al. A critical reassessment of ambulance service airway management in prehospital care: joint Royal Colleges Ambulance Liaison Committee Airway Working Group, June 2008. Emerg Med J. 2010;27(3):226-33. https://doi. org/10.1136/emj.2009.082115.

21. Grissom TE, Sappenfield J, Galvagno SM Jr, Cherry SV, Chang YC, Hu PF. Performance assessment in airway management training for nonanesthesiology trainees: an analysis of 4,282 airway procedures performed at a level-1 trauma center. Anaesthesia. 2014;120(1):185-95. https://doi.org/10.1097/ALN.0000000000000064.

22. Fouche PF, Stein C, Simpson P, Carlson JN, Doi SA. Nonphysician Out-ofHospital Rapid Sequence Intubation Success and Adverse Events: A Systematic Review and Meta-Analysis. Ann Emerg Med. 2017;70(4):449-59.e20.

23. Crewdson K, Lockey DJ, Røislien J, Lossius HM, Rehn M. The success of prehospital tracheal intubation by different pre-hospital providers: a systematic literature review and meta-analysis. Crit Care. 2017;21(1):31. https://doi.org/1 0.1186/s13054-017-1603-7.

24. Warner KJ, Carlbom D, Cooke CR, Bulger EM, Copass MK, Sharar SR. Paramedic training for proficient prehospital endotracheal intubation. Prehosp Emerg Care. 2010;14(1):103-8. https://doi.org/10.3109/10903120903144858.

25. Gillett B, Saloum D, Aghera A, Marshall JP. Skill proficiency is predicted by intubation frequency of emergency medicine attending physicians. West $J$ Emerg Med. 2019;20(4):601-9. https://doi.org/10.5811/westjem.2019.6.42946.

26. Burgess MR, Crewdson K, Lockey DJ, Perkins ZB. Prehospital emergency anaesthesia: an updated survey of UK practice with emphasis on the role of standardisation and checklists. Emerg Med J. 2018;35(9):532-7. https://doi. org/10.1136/emermed-2017-206592. 
27. Haynes AB, Weiser TG, Berry WR, Lipsitz SR, Breizat AH, Dellinger EP, et al. A surgical safety checklist to reduce morbidity and mortality in a global population. N Engl J Med. 2009;360(5):491-9. https://doi.org/10.1056/ NEJMsa0810119.

28. de Vries EN, Prins HA, Crolla RM, den Outer AJ, van Andel G, van Helden SH, et al. Effect of a comprehensive surgical safety system on patient outcomes. N Engl J Med. 2010;363(20):1928-37. https:/doi.org/10.1056/NEJMsa0911535.

29. Smith KA, High K, Collins SP, Self WH. A preprocedural checklist improves the safety of emergency department intubation of trauma patients. Acad Emerg Med. 2015;22(8):989-92. https://doi.org/10.1111/acem.12717.

30. Turner JS, Bucca AW, Propst SL, Ellender TJ, Sarmiento EJ, Menard LM, et al. Association of Checklist use in endotracheal intubation with clinically important outcomes: a systematic review and meta-analysis. JAMA Netw Open. 2020;3(7):e209278. https://doi.org/10.1001/jama networkopen.2020.9278.

31. Janz DR, Semler MW, Joffe AM, Casey JD, Lentz RJ, deBoisblanc BP, et al. A multicenter randomized trial of a checklist for endotracheal intubation of critically ill adults. Chest. 2018;153(4):816-24. https://doi.org/10.1016/j.chest.2 017.08.1163.

32. Conroy MJ, Weingart GS, Carlson JN. Impact of checklists on peri-intubation care in ED trauma patients. Am J Emerg Med. 2014;32(6):541-4. https://doi. org/10.1016/j.jem.2014.02.006.

33. Klingberg C, Kornhall D, Gryth D, Krüger AJ, Lossius HM, Gellerfors M. Checklists in pre-hospital advanced airway management. Acta Anaesthesiol Scand. 2020;64(1):124-30. https://doi.org/10.1111/aas.13460.

34. Jaber S, Jung B, Corne P, Sebbane M, Muller L, Chanques G, et al. An intervention to decrease complications related to endotracheal intubation in the intensive care unit: a prospective, multiple-center study. Intensive Care Med. 2010;36(2):248-55. https://doi.org/10.1007/s00134-009-1717-8.

35. Clay-Williams R, Colligan L. Back to basics: checklists in aviation and healthcare. BMJ Qual Saf. 2015;24(7):428-31. https://doi.org/10.1136/bmjgs-2015-003957.

36. Burian BK, Clebone A, Dismukes K, Ruskin KJ. More than a tick box: medical checklist development, design, and use. Anesth Analg. 2018;126(1):223-32. https://doi.org/10.1213/ANE.0000000000002286.

37. Frerk C, Mitchell VS, McNarry AF, Mendonca C, Bhagrath R, Patel A, et al. Difficult airway society 2015 guidelines for management of unanticipated difficult intubation in adults. Br J Anaesth. 2015;115(6):827-48. https://doi. org/10.1093/bja/aev371.

38. Higgs A, McGrath BA, Goddard C, Rangasami J, Suntharalingam G, Gale $\mathrm{R}$, et al. Guidelines for the management of tracheal intubation in critically ill adults. Br J Anaesth. 2018;120(2):323-52. https://doi.org/10.1 016/j.bja.2017.10.021.

39. Pandit JJ, Cook TM, editors. NAP5 Accidental Awareness during General Anaesthesia in the United Kingdom and Ireland: Chapter 6; 2014.

40. Lyon RM, Perkins ZB, Chatterjee D, Lockey DJ, Russell MQ, Kent S, et al. Significant modification of traditional rapid sequence induction improves safety and effectiveness of pre-hospital trauma anaesthesia. Crit Care. 2015; 19(1):134. https://doi.org/10.1186/s13054-015-0872-2.

41. Schwedler M, Miletich DJ, Albrecht RF. Cerebral blood-flow and metabolism following ketamine administration. Can Anaesth Soc J. 1982;29(3):222-6. https://doi.org/10.1007/BF03007120.

42. Zeiler FA, Teitelbaum J, West M, Gillman LM. The ketamine effect on ICP in traumatic brain injury. Neurocrit Care. 2014;21(1):163-73. https://doi.org/10.1 007/s12028-013-9950-y.

43. Bruder EA, Ball IM, Ridi S, Pickett W, Hohl C. Single induction dose of etomidate versus other induction agents for endotracheal intubation in critically ill patients. Cochrane Database Syst Rev. 2015;1 (1):Cd010225.

44. Marsch SC, Steiner L, Bucher E, Pargger H, Schumann M, Aebi T, et al. Succinylcholine versus rocuronium for rapid sequence intubation in intensive care: a prospective, randomized controlled trial. Crit Care. 2011; 15(4):R199. https://doi.org/10.1186/cc10367.

45. Tran DT, Newton EK, Mount VA, Lee JS, Wells GA, Perry JJ. Rocuronium versus succinylcholine for rapid sequence induction intubation. Cochrane Database Syst Rev. 2015;2015(10):Cd002788.

46. Hartley EL, Alcock R. Rocuronium versus Suxamethonium: a survey of first-line muscle relaxant use in UK Prehospital rapid sequence induction. Prehosp Disaster Med. 2015;30(2):184-6. https://doi.org/10.1017/S1049023X15000047.

47. Chambers D, Paulden M, Paton F, Heirs M, Duffy S, Hunter JM, et al. Sugammadex for reversal of neuromuscular block after rapid sequence intubation: a systematic review and economic assessment. $\mathrm{Br} J$ Anaesth. 2010;105(5):568-75. https://doi.org/10.1093/bja/aeq270.
48. Gellerfors M, Fevang E, Bäckman A, Krüger A, Mikkelsen S, Nurmi J, et al. Pre-hospital advanced airway management by anaesthetist and nurse anaesthetist critical care teams: a prospective observational study of 2028 pre-hospital tracheal intubations. Br J Anaesth. 2018;120(5):1103-9. https:// doi.org/10.1016/j.bja.2017.12.036.

49. Alkhouri H, Vassiliadis J, Murray M, Mackenzie J, Tzannes A, McCarthy S, et al. Emergency airway management in Australian and New Zealand emergency departments: a multicentre descriptive study of 3710 emergency intubations. Emerg Med Australas. 2017;29(5):499-508. https://doi.org/1 $0.1111 / 1742-6723.12815$

50. Wafaisade A, Caspers M, Bouillon B, Helm M, Ruppert M, Gäßler M. Changes in anaesthetic use for trauma patients in German HEMS - a retrospective study over a ten-year period. Scand J Trauma Resusc Emerg Med. 2019; 27(1):23. https://doi.org/10.1186/s13049-019-0603-9.

51. Algie CM, Mahar RK, Tan HB, Wilson G, Mahar PD, Wasiak J. Effectiveness and risks of cricoid pressure during rapid sequence induction for endotracheal intubation. Cochrane Database Syst Rev. 2015;(11):CD01 1656. https://doi.org/10.1002/14651858.CD011656.pub2.

52. Birenbaum A, Hajage D, Roche S, Ntouba A, Eurin M, Cuvillon P, et al. Effect of cricoid pressure compared with a sham procedure in the rapid sequence induction of anesthesia: the IRIS randomized clinical trial. JAMA Surg. 2019; 154(1):9-17.

53. Gwinnutt M, Gwinnutt J, Robinson D. The use of cricoid pressure during rapid sequence induction in trauma patients - UK and European practice compared. Trauma. 2016;18(1):21-7. https://doi.org/10.1177/1460408615615599.

54. Soar J, Nolan JP, Bottiger BW, Perkins GD, Lott C, Carli P, et al. European resuscitation council guidelines for resuscitation 2015: section 3. Adult advanced life support. Resuscitation. 2015;95:100-47. https://doi.org/10.101 6/j.resuscitation.2015.07.016.

55. Jensen AG, Callesen T, Hagemo JS, Hreinsson K, Lund V, Nordmark J, et al. Scandinavian clinical practice guidelines on general anaesthesia for emergency situations. Acta Anaesthesiol Scand. 2010;54(8):922-50. https:// doi.org/10.1111/j.1399-6576.2010.02277.x.

56. Piepho T, Cavus E, Noppens R, Byhahn C, Dorges V, Zwissler B, et al. S1 guidelines on airway management : guideline of the German society of anesthesiology and intensive care medicine. Anaesthesist. 2015;64(Suppl 1): 27-40. https://doi.org/10.1007/s00101-015-0109-4.

57. Bodily JB, Webb HR, Weiss SJ, Braude DA. Incidence and duration of continuously measured oxygen desaturation during emergency department intubation. Ann Emerg Med. 2016;67(3):389-95. https://doi.org/10.1016/j.a nnemergmed.2015.06.006.

58. Binks MJ, Holyoak RS, Melhuish TM, Vlok R, Hodge A, Ryan T, et al. Apnoeic oxygenation during intubation in the intensive care unit: a systematic review and meta-analysis. Heart Lung. 2017;46(6):452-7. https://doi.org/10.1 016/j.hrtlng.2017.08.001.

59. Silva LOJE, Cabrera D, Barrionuevo P, Johnson RL, Erwin PJ, Murad MH, et al. Effectiveness of apneic oxygenation during intubation: a systematic review and meta-analysis. Ann Emerg Med. 2017;70(4):483-94 e11. https://doi.org/1 0.1016/j.annemergmed.2017.05.001.

60. Lodenius A, Piehl J, Ostlund A, Ullman J, Fagerlund MJ. Transnasal humidified rapid-insufflation ventilatory exchange (THRIVE) vs. facemask breathing pre-oxygenation for rapid sequence induction in adults: a prospective randomised non-blinded clinical trial. Anaesthesia. 2018;73(5): 564-71. https://doi.org/10.1111/anae.14215.

61. Mariyawelvam MSD, Wijewardena G, Blunt M, Young P. Transnasal humidified rapid insufflation ventilatory exchange for pre-oxygenation and apnoeic oxygenation during rapid sequence inductin. Crit Care. 2015; 19(Suppl 1):208

62. Wimalasena Y, Burns B, Reid C, Ware S, Habig K. Apneic oxygenation was associated with decreased desaturation rates during rapid sequence intubation by an Australian helicopter emergency medicine service. Ann Emerg Med. 2015;65(4):371-6. https://doi.org/10.1016/..annemergmed.2014.11.014.

63. Caputo N, Azan B, Domingues R, Donner L, Fenig M, Fields D, et al. Emergency department use of apneic oxygenation versus usual care during rapid sequence intubation: a randomized controlled trial (the ENDAO trial). Acad Emerg Med. 2017;24(11):1387-94. https://doi.org/10.1111/acem.13274.

64. Crewdson K, Heywoth A, Rehn M, Sadek S, Lockey D. Apnoeic oxygenation for emergency anaesthesia of pre-hospital trauma patients. Scand J Trauma Resusc Emerg Med. 2021;29(1):10. https://doi.org/10.1186/s13049-020-00817-7.

65. Casey JD, Janz DR, Russell DW, Vonderhaar DJ, Joffe AM, Dischert KM, et al. Bag-mask ventilation during tracheal intubation of critically ill 
adults. N Engl J Med. 2019;380(9):811-21. https://doi.org/10.1056/ NEJMoa1812405.

66. Semler MW, Janz DR, Russell DW, Casey JD, Lentz RJ, Zouk AN, et al. A multicenter, randomized trial of ramped position vs sniffing position during endotracheal intubation of critically ill adults. Chest. 2017;152(4):712-22. https://doi.org/10.1016/j.chest.2017.03.061.

67. Lewis SR, Butler AR, Parker J, Cook TM, Smith AF. Videolaryngoscopy versus direct laryngoscopy for adult patients requiring tracheal intubation. Cochrane Database Syst Rev. 2016;11(11):Cd011136.

68. Yeatts DJ, Dutton RP, Hu PF, Chang YW, Brown CH, Chen H, et al. Effect of video laryngoscopy on trauma patient survival: a randomized controlled trial. J Trauma Acute Care Surg. 2013;75(2):212-9. https://doi.org/10.1097/TA. 0b013e318293103d.

69. Kreutziger J, Hornung S, Harrer C, Urschl W, Doppler R, Voelckel WG, et al. Comparing the McGrath mac video laryngoscope and direct laryngoscopy for Prehospital emergency intubation in air rescue patients: a multicenter, randomized, Controlled Trial. Crit Care Med. 2019;47(10):1362-70. https://doi. org/10.1097/CCM.0000000000003918.

70. Cook TM, Kelly FE. A national survey of videolaryngoscopy in the United Kingdom. Br J Anaesth. 2017;118(4):593-600. https://doi.org/10.1 093/bja/aex052.

71. Cook TM, El-Boghdadly K, McGuire B, McNarry AF, Patel A, Higgs A. Consensus guidelines for managing the airway in patients with COVID-19 guidelines from the difficult airway society, the Association of Anaesthetists the Intensive Care Society, the Faculty of Intensive Care Medicine and the Royal College of Anaesthetists. Anaesthesia. 2020;75(6):785-99. https://doi. org/10.1111/anae.15054.

72. Difficult Airway Society. Difficult Airway Guidelines. 2020. https://das.uk. com/. Accessed 22 Jan 2021.

73. Driver $B E$, Prekker $M E$, Klein $L R$, Reardon RF, Miner JR, Fagerstrom ET, et al. Effect of use of a Bougie vs endotracheal tube and Stylet on first-attempt intubation success among patients with difficult airways undergoing emergency intubation: a randomized clinical trial. JAMA. 2018;319(21):217989. https://doi.org/10.1001/jama.2018.6496.

74. Grmec S, Mally S. Prehospital determination of tracheal tube placement in severe head injury. Emerg Med J. 2004;21(4):518-20.

75. Raitt J, Hudgell J, Knott H, Masud S. Key performance indicators for pre hospital emergency Anaesthesia - a suggested approach for implementation. Scand J Trauma Resusc Emerg Med. 2019;27(1):42. https:// doi.org/10.1186/s13049-019-0610-x.

76. Checketts MR, Alladi R, Ferguson K, Gemmell L, Handy JM, Klein AA, et al. Recommendations for standards of monitoring during anaesthesia and recovery 2015: Association of Anaesthetists of Great Britain and Ireland. Anaesthesia. 2016 Jan;71(1):85-93. https://doi.org/10.1111/anae.13316.

77. Stephens $C T$, Kahntroff S, Dutton RP. The success of emergency endotracheal intubation in trauma patients: a 10-year experience at a major adult trauma referral center. Anesth Analg. 2009;109(3):866-72. https://doi. org/10.1213/ane.0b013e3181ad87b0.

78. Aziz S, Foster E, Lockey DJ, Christian MD. Emergency scalpel cricothyroidotomy use in a prehospital trauma service: a 20-year review. Emerg Med J. 2021. emermed-2020-210305. https://doi.org/10.1136/ emermed-2020-210305. Epub ahead of print.

79. Natt BS, Malo J, Hypes CD, Sakles JC, Mosier JM. Strategies to improve first attempt success at intubation in critically ill patients. Br J Anaesth. 2016; 117(Suppl 1):i60-i8. https://doi.org/10.1093/bja/aew061.

80. Sakles JC, Augustinovich CC, Patanwala AE, Pacheco GS, Mosier JM. Improvement in the safety of rapid sequence intubation in the emergency department with the use of an airway continuous quality improvement program. West J Emerg Med. 2019;20(4):610-8. https://doi.org/10.5811/ westjem.2019.4.42343.

\section{Publisher's Note}

Springer Nature remains neutral with regard to jurisdictional claims in published maps and institutional affiliations.

Ready to submit your research? Choose BMC and benefit from:

- fast, convenient online submission

- thorough peer review by experienced researchers in your field

- rapid publication on acceptance

- support for research data, including large and complex data types

- gold Open Access which fosters wider collaboration and increased citations

- maximum visibility for your research: over $100 \mathrm{M}$ website views per year

At BMC, research is always in progress.

Learn more biomedcentral.com/submissions 